\title{
Art Museums and the Global Tourist: Experience Centers in Experiencescapes
}

\author{
By Mark Pennings*
}

\begin{abstract}
Art museums are playing an important role is attracting cultural tourists to global cities and regions. Traditionally, art museums were primarily known for their didactic role. In a post-avant-garde era however museums are more focused on appealing to a broader clientele that want art to be novel and entertaining. Art museums have also come to play a greater role in gentrification projects and cultural precincts. This is because they are ideally suited for tourist-centric environments that offer a variety of immersive sensory experiences, and combine museums (often designed by star-architects), international hotels, restaurants, high-end shopping zones, and other leisure platforms. These "experiencescapes" include Port Maravilha urban waterfront development in Rio de Janiero, the Shanghai Bund, and the Broad project in Los Angeles. The Museum of Old and New Art in Hobart Australia is a boutique player in the global market for experiencescapes. It is smaller than many of its competitors and is situated in a remote part of the world, yet it has made an important contribution to Tasmania's tourism industry.
\end{abstract}

Keywords: Art museums, Cultural precincts and infrastructure, Cultural tourism, Experience-scapes.

\section{Introduction}

Our global culture places increasing value on leisure and entertainment, and the tourism industries are ideally placed to cater to those experiences. Art museums are significant in this regard because they offer engaging cultural, leisurely and entertaining options. They are also often located at the heart of cultural precincts, or experiencescapes, which are civic infrastructures that are customized to service the experiential demands of an increasingly mobile populace in a lucrative tourist market (Ek 2005, Klingmann 2010, Lonsway 2009, O'Dell 2005). This phenomenon has been allied with the changing function of art museums: from didactic institutions to entertainment or experience centers, and this development has greatly enhanced the cultural and economic standing of these museums because they help attract global tourists to experiencescapes.

The Museum of Old and New Art (MONA) in Hobart, Tasmania, is making a unique contribution to this development (Picture 1). The museum houses the private art collection of David Walsh, a gambling entrepreneur. Its contribution to the Tasmanian tourism industry (and a struggling local economy) has exceeded the wildest of expectations, and has done so on its own idiosyncratic terms. The most famous global art museums are known for their

\footnotetext{
${ }^{*}$ Senior Lecturer, Queensland University of Technology, Australia.
} 
spectacular "starchitect" designed exteriors, but MONA's reputation is based on a spectacular interior setting (it is built into a sandstone cliff on a peninsula abutting the Derwent River). It also showcases an innovative exhibition design, and provides engaging digital applications for visitor use. MONA might be understood as a boutique experience center that is making a name for itself in a competitive, and corporate-dominated, cultural tourist marketplace of experiencescapes.

Picture 1. Museum of Old and New Art, Hobart

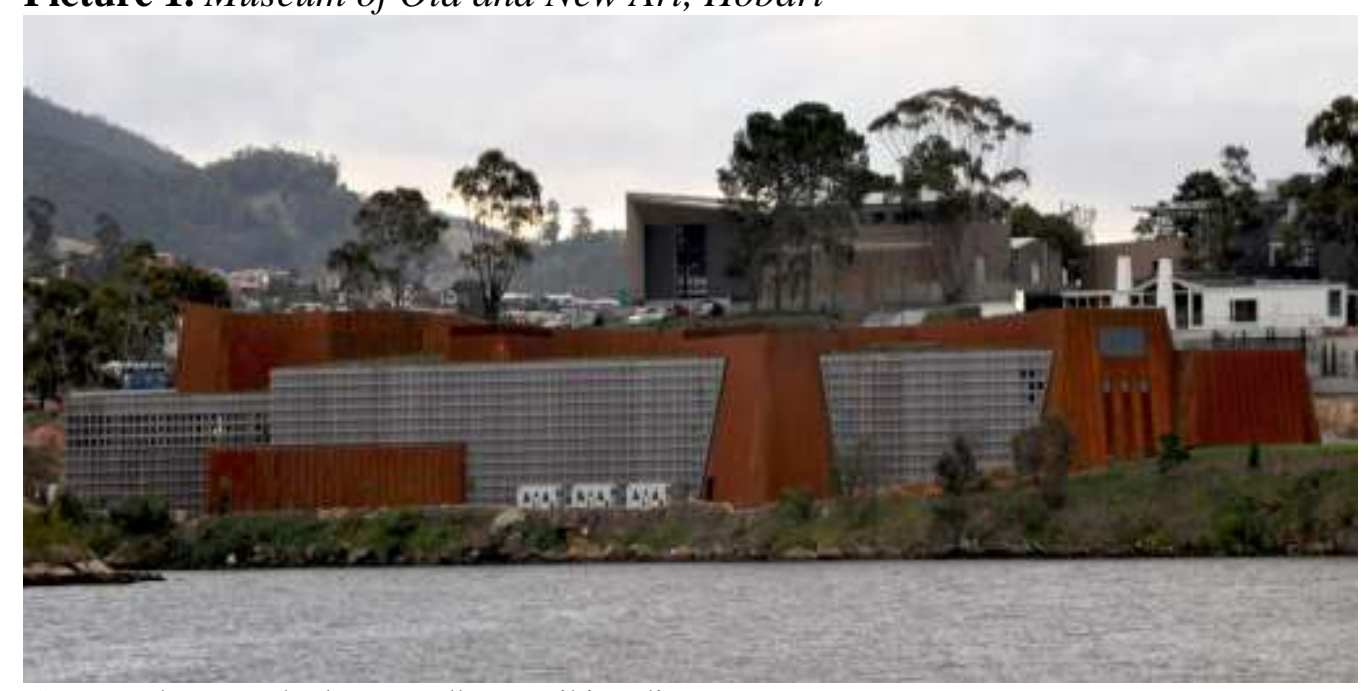

Source: Photography by Barrylb on Wikimedia commons.

https://upload.wikimedia.org/wikipedia/commons/c/c3/MONA_2.jpg

This paper will examine the importance of tourism to global cities, and provides a summary of the way in which art museums have adapted to this lucrative market by becoming experience centers, where entertainment and education converge. Art museums have also become ideal venues in experiencescapes, because they complement a range of cultural and retail opportunities that enhance the tourist experience and the brand recognition of a city. Early innovators such as the Centre Georges Pompidou in Paris, and the Guggenheim Museum in Bilbao were some of the first to establish this type of museum. These are iconic buildings that add brand value to global cities, and were designed by high profile starchitects. Many global cities are deploying corporate principles to build experiencescapes on a large scale, but MONA in Tasmania has demonstrated that small museums can successfully vie with larger competitors and thus offers an interesting case study for analysis.

\section{The Boom in Tourism}

Tourism has always been an important sector in the global economy, but in the twenty-first century it is growing at a phenomenal rate. In 2014 there were an estimated 1.87 billion tourists (which is 1 in 7 of the global population), of which 107 million were from mainland China (an increase of 20\% from 2013). 
Chinese tourists now number one in ten of all travellers, and by 2030 their numbers are predicted to grow to 1.8 billion and will spend an estimated $\$ 1.8$ trillion (Travel Daily News 2014). These projections suggest global tourism will double in just over a decade. Many cities and countries however have already been experiencing spectacular tourist visitations: Berlin reported a record 12 million visitors in 2014, and Japan recently recorded 1.7 million tourist visits in April, up 43.3\% from 2014, and following record visits in February and March. The Japanese government is investing in plans to attract 20 million inbound tourists by 2020 (when Tokyo will host the 2020 Olympic Games), and believes this influx will create 400,000 new jobs.

The importance of tourism to economic prosperity is well known. For example, in 2014 one sixth of Greeks were employed in tourism, and $16.4 \%$ of this country's GDP derived from tourism. Not surprisingly, the Greek government is looking to tourism to help overcome its present economic crisis.

\section{The Art Museum as Experience Center}

In the late 1980s as neoliberalism consolidated its influence over economic and political life many publically funded (art) museums were placed under pressure to appeal to broader audiences (Robertson 2011, Stallabrass 2004, Wu 2003, Yúdice 2004). This fed into the field of "new museology" where museums moved away from the didactic use of collections and devoted more resources to attracting broader audiences with blockbuster shows, biennials, the display of celebrity artists as brands, and artwork that was novel and participatory. Museums initiated a range of entertainment activities and events that were traditionally outside the purview of art, such as jazz nights, wine tasting sessions, and festival-type events (a trend called "Festivalism"). Art museums hosted social occasions and participatory-style art events during the 1960s, but in recent times this practice has become widespread as museums have become more like cultural experience centers and have shifted from museums "of interpretation to one of experience" (Foster 2011: 119).

As cultural infotainment centers art museums offer transitory installations and blockbuster exhibitions that emphasize "flexibility and spectacle, while the inclusion of retail spaces such as bookshops and cafes align the museum with the world of consumerism and leisure" (Huppatz 2008: 200). Art museums are therefore re-modeling aesthetic experience into dynamic, entertaining, interactive, immersive, and participatory events, rather than being exclusively devoted to protecting and displaying precious objects. For example, the Tate Modern in London sells the art experience through traditional group and private tours, multimedia experiences enabled by guides involving video, interactive games, and art-related music. There are iPhone apps for visitors to play games with artwork, and an Interactive zone where visitors can read about art, play hands-on games, and watch films about art in the Tate Modern's collection. There has also been a Cubist playground with giant objects from Cubist still life paintings. In addition, it has the large Turbine Hall exhibition 
space where well-known art works such as Carsten Höller's Test Site (2006) where visitors could use playground slides, and Olaf Eliasson's The Weather Project (2003) - an environmental and immersive simulation of nature with a golden sun - are typical of new global art that appeals to broad audiences, encourages physical interaction with art, and have a trans-cultural perspective as no particular expertise in art or language is required to engage with it. Artists have been producing participatory-type artworks for many years, and elicited creative engagement from the general public in an inclusive sense, but what was once an avant-garde activity that sought to instigate a progressive transformation of social values has now often become a post-avant-garde style of art that primarily reinforces the entertainment goals of global cultural zones.

Art museums have always appealed to tourists, but as they have become more like entertainment venues they are playing a more important role in attracting tourists to cultural precincts and experiencescapes. In New York for example, $79 \%$ of the 50.5 million foreigners who visited that city in 2012 attended a cultural institution. A sizeable portion of these visitors attended the major art museums MoMA and the Guggenheim. Of those visitors to MoMA only $15 \%$ were from the New York area, while for the Guggenheim that figure was around $13 \%$ out of 1.18 million annual visitors. ${ }^{1}$ These statistics demonstrate the vital role art museums play in attracting global tourists and the way they can enhance economic benefits to their city of origin.

\section{Place Marketing and Art Museums}

Cities invest considerable resources into promoting their unique cultural wares in an intensely competitive global environment. To this end, "The marketing of experiences has become essential to making cities attractive, and in that way, attracting visitors" (Jenson 2005: 146). The experiences that are publicized are associated with a wide variety of sites including stadiums, music halls, theme parks, festival marketplaces, leisure parks, art museums, retail shopping, cultural centers, and may also include distinctive urban planning, gastronomic distinctiveness, or other cultural attractions. All of these contribute to the process of "place marketing", which involves the marketable framing of specific cities, urban precincts and regions. Cities seek to appeal to tourists by promoting existing cultural infrastructure (such as the Parthenon in Athens), and may construct urban precincts that combine cultural institutions, shopping districts and luxury accommodation. These urban and regional infrastructures are the new experiencescapes that can be developed, branded and promoted in an attempt to claim a lucrative share of the global tourist market. $^{2}$

\footnotetext{
${ }^{1}$ This is part of larger trend in which art museums have become increasingly attractive venues for populist audiences. For example, in the USA visitation statistics have risen "from approximately 1 in 10 citizens visiting museums annually during the 1970 s to 2-3 in every 5 citizens visiting museums annually by 2000" (Falk and Dierking 2000: 2).

${ }^{2}$ New York City's "branding" in the late 1970s was a pioneer in this field.
} 
Picture 2. Pompidou Centre, Paris

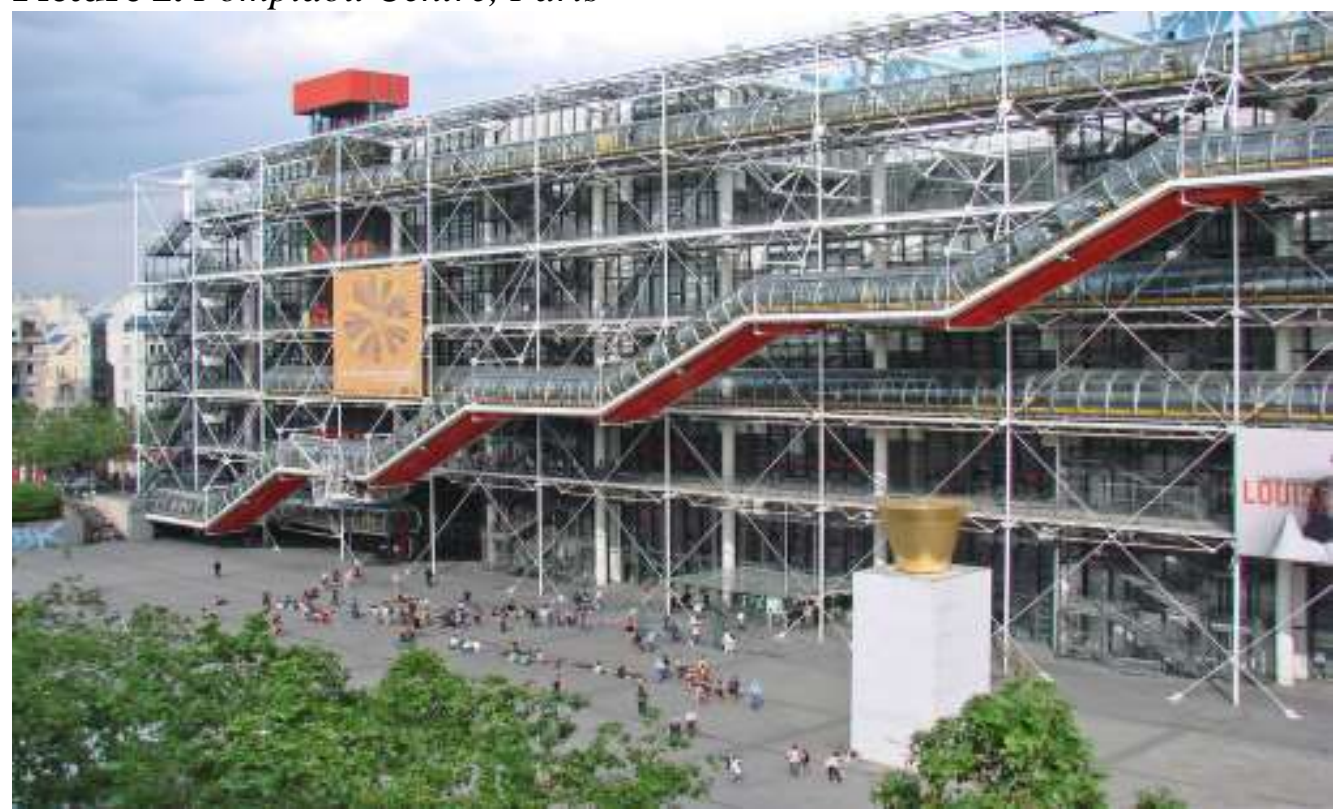

Source: Photography by Jean-Pierre Dalbéra. flickr.com/photos/dalbera/sets/72157603469783422/.

Art museums have had a significant influence on the branding, design and orientation of experiencescapes. One of the landmarks in this place marketing was Richard Rogers' and Renzo Piano's Centre Georges Pompidou in Paris (1979). This edifice announced an important moment in the transition of museums from didactic institution to tourist-centric experience center, and opened the era of auteur museum buildings designed to attract a public eager for the consumption of spectacles (Picture 2). This building has an art collection, but is also a multidisciplinary cultural "living space" with public library, music venue, and center for industrial design, workshops and conference sites. It has attracted millions of tourists, and is an iconic Pop Artstyle building that looks like a toy factory outside (surrounded by plazas), and a shopping mall inside. It is situated in the Beaubourg tourist precinct, and was intended to be a catalyst for urban regeneration and the gradual gentrification of Paris' Marais area. The Pompidou showed how important an iconic, architectural spectacle could be in branding and lifting the profile of a city in the international marketplace. It also supplemented established iconic structures like the Eiffel Tower, and if the tower embodied industrial modernity and the celebration of the engineer; the Pompidou served to symbolize the values of postmodern culture and its dedication to leisure, entertainment and lifestyle experience values. Such spaces also needed to cater for new developments in neo-avant-garde art practices such as Conceptual Art, Installation, Performance Art, and Video Art, which required new kinds of exhibition spaces that needed to be multi-purpose in orientation. 
Picture 3. Guggenheim Museum, Bilbao

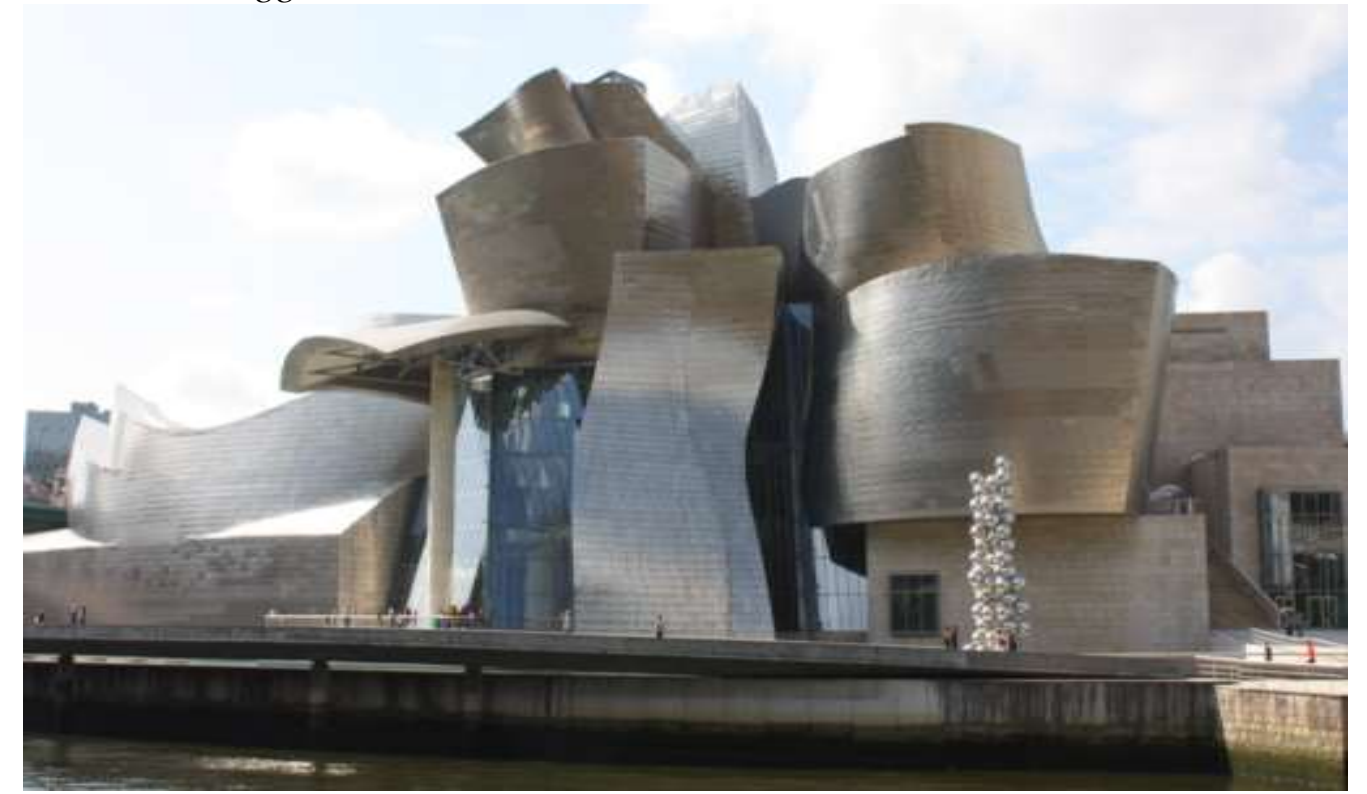

Source: Photography by Ardfern. https://commons.wikimedia.org/wiki/File:Guggenheim_Mus eum,_Bilbao,_July_2010_\%2806\%29.JPG.

Another star in the firmament of art museums that have made critical contributions to successful experiencescapes is the Guggenheim Bilbao (erected in 1997 and designed by starchitect Frank Gehry). In an attempt to revive this dilapidated Galician industrial city its authorities hired Gehry and the Guggenheim to construct a museum with an iconic design. It has come to symbolize the city's ambition to become dynamic and relevant, and the one million tourists it attracts every year is testament to its success. Its iconic design also branded the city with a distinctive aesthetic profile that added cultural and social prestige in the global tourist marketplace. It also revitalized the city and led to the development of additional urban infrastructure projects (Picture 3).

\section{Experiencescapes}

The experiencescape - with its cultural heritage sites, shops, luxury apartments and hotels, and parks - represents a commercial streamlining of urban centers into marketable lifestyle environments. ${ }^{1}$ Tom O'Dell has provided a useful definition of experiencescapes as:

sites of market production, the spaces within which experiences are staged and consumed [and] can be likened to stylized landscapes that are strategically planned, laid out and designed. They are ... landscapes of experience ... that are not only organized by producers (from place

\footnotetext{
1 Entire cities have also been promoted as cultural experiencescapes, as with Europe's European Capital of Culture (whose current holders are Mons and Plzen).
} 
marketers and city planners to local private enterprises), but are also actively sought after by consumers. They are spaces of pleasure, enjoyment and entertainment (O’Dell 2005: 16). ${ }^{1}$

Experiencescapes often express the privatized re-organization of urban infrastructures to generate and satisfy tourist demands and markets. This is a global phenomenon, and some notable recent examples of this tendency include Shanghai, where the Rockbund Art Museum sits at the "cultural heart" of a riverside promenade called the Shanghai Bund (Picture 4). This extensive urban redevelopment scheme has a usable floor area of 102,000 square meters and will offer luxury apartments, offices, malls and cultural facilities. It is being built by developer Sinolink Worldwide Holdings and the Rockefeller Group at a cost of 240 billion Euros. When finished it will cover six city blocks and will include seven heritage buildings in one of Asia's most valuable slices of real estate. The gentrification of the Shanghai Bund "fits seamlessly into globalization rhetoric located between glamour and luxury, with historical building fabric used as the crowning element of an orientation in progress" (Krasny 2010: 20).

Picture 4. Promenade at the Shanghai Bund

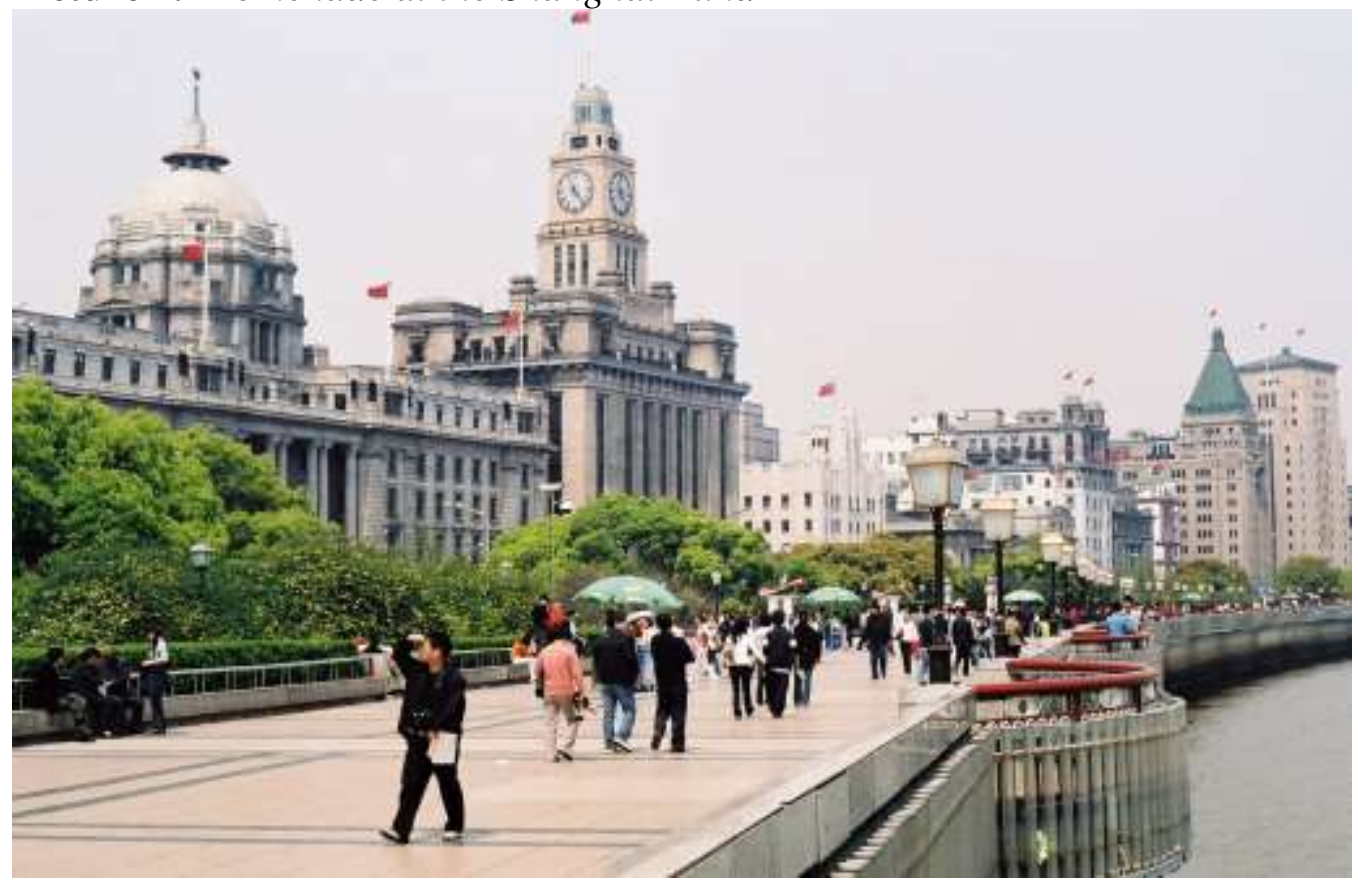

Source: Photography by Georgio. http://creativecommons.org/licenses/by-sa/3.0/.

\footnotetext{
${ }^{1}$ These environments are also a kind of business ecosystem that operates in a particular geographic location and contains a network of cultural and business interests that intersect for mutual benefit. See Mirva Peltoniemi and Elissa Vuori (2004). J.F. Moore (1996) suggested a dubious conflation of economic and biological systems of existence, but his notions of the business eco-system are useful when theorizing the advantages of business environments when treated as a larger system of interaction, dependency and mutual gain.
} 
The United States has been particularly active in creating major experiencescape projects where art museums play a central role. For example, Los Angeles is in the process of constructing a new cultural precinct that will contain "The Broad" a new contemporary art museum (Picture 5). It will be funded by a $\$ 200$ million endowment from entrepreneur Eli Broad and is being designed by starchitects Diller, Scofidio + Renfro. The precinct will include a 32-metre long escalator tube as a novelty attraction for tourists. The Broad Art Museum will share Grand Avenue with the Museum of Contemporary Art (MOCA) and the Frank Gehry designed Walt Disney Concert Hall. The Broad museum has been described as "not just a $\$ 140 \mathrm{~m}$ building. It's at the core of a cultural boom" (Edgers 2014: 41). In Colorado the Denver Art Museum, designed by another starchitect Daniel Libeskind, has a distinctive prow shape, which can be readily branded as an icon. This museum is also part of an urban renewal project that is gentrifying the surrounding area. Miami City (which already hosts the popular Art Basel Miami cultural event) is also undertaking a major redevelopment project to rejuvenate the downtown neighborhood of Miami Beach's 17th Street corridor. This will involve the construction of a New World Center (designed by Frank Gehry), the Adrienne Arsht Center for Performing arts, a Museum Park, and other buildings.

Picture 5. The Broad Museum, Los Angeles (under construction)

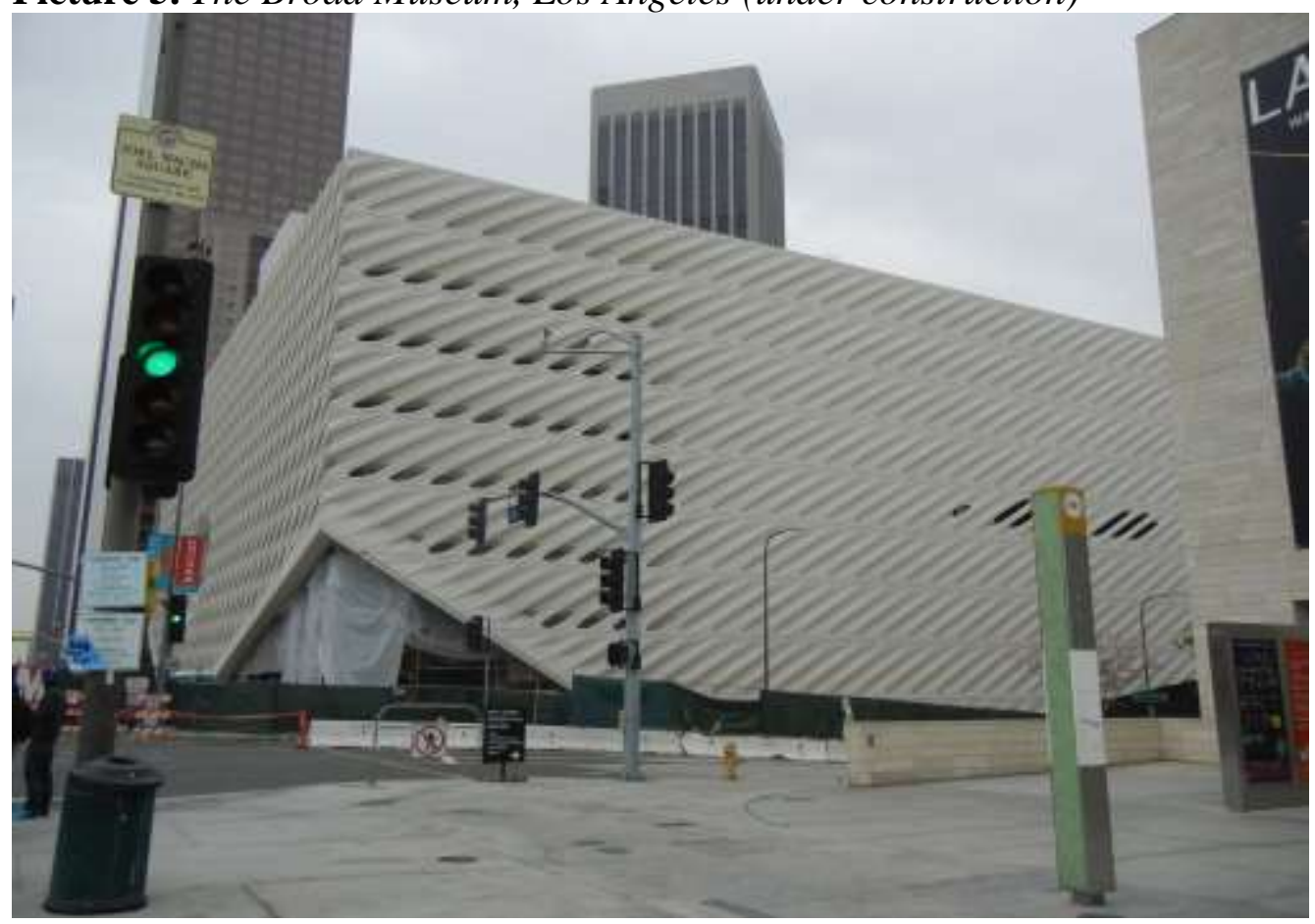

Source: Photography by Bahooka. http://creativecommons.org/licenses/by-sa/4.0.

The Brazilian government is investing million of dollars in a gentrification project called Porto Maravilha (Marvelous Port). This experiencescape will be financed by corporations such as Tishman Speyer, the Trump Organization and the Westfield Group, and will transform a precinct known for its impoverished 
favelas into luxury towers, hotels, and shopping malls. At its heart is the art museum Museu de Arte do Rio (MAR), which was built in 2013 (Picture 6). This cultural center (designed by architects Bernardes and Jacobsen Arquitetura) has a distinctive flowing roofline that will establish its iconic credentials, and "is the first landmark of the port-area renewal project, thus heralding a series of transformations that seek to turn the site into a predominantly corporate and tourist district ... [and it will be] the "cultural anchor" of Porto Maravilha" (Martins 2014: 284). This ambitious cultural precinct also possesses a style of urban infrastructure that is conceived by corporations to appeal to affluent locals and visitors who are presented with a standardized range of services such as art museums, prestige shopping malls, luxury apartment blocks, yachting facilities, etc.

Picture 6. Museu de Arte do Rio (Architects: Bernardos + Jaconsen), Porto Marvilha, Rio de Janiero

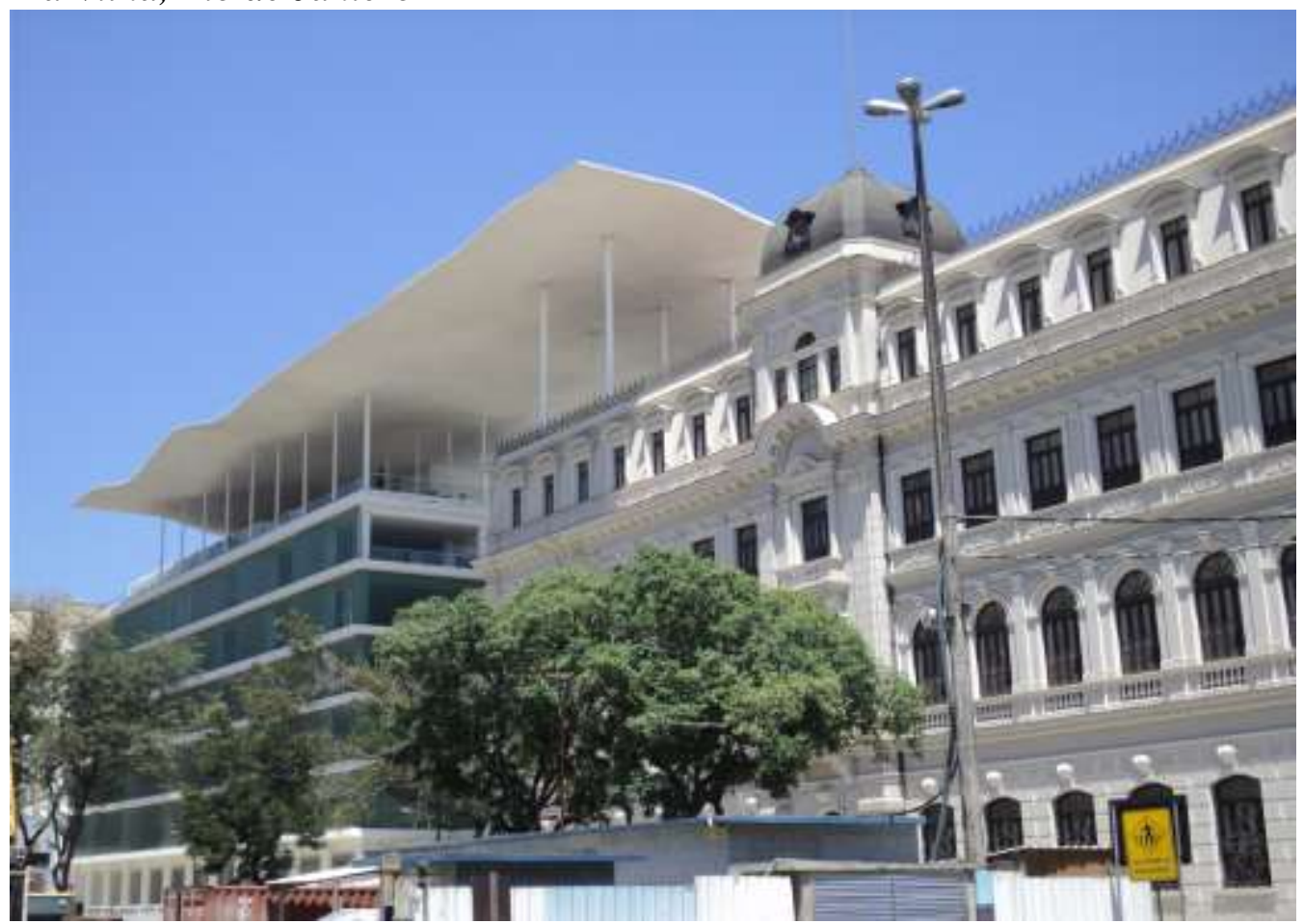

Source: Photography by Mwaldeck http://creativecommons.org/licenses/by-sa/3.0.

\section{Museum of Old and New Art (MONA)}

MONA in Tasmania is not part of a massive urban rejuvenation project. Instead, it is a boutique art experience center that nonetheless plays an important role in Hobart's experiencescape, and has managed to gain a share in a competitive global tourist market. It has achieved this by surprising means. Unlike most other endeavors of this nature, owner David Walsh did not employ a global celebrity architect to create his building; opting instead for GreekAustralian, Sydney architect Nonda Katsalidis. Moreover, this edifice does not 
rely on a spectacular exterior design to attract attention, for its most unique and distinguishing features are inside the building.

The exterior of MONA is a somber, ochre colored building that looks more like a warehouse than an art museum. The visitor arrives by ferry at a small dock site, and from there ascends a flight of stairs that leads to a broad open plaza dotted with public artworks. These do not appear to lead anywhere in particular, and there are no signs that provide directions to what is a rather nondescript entrance. There is no grand public-styled entrance inside the building, and when one enters the "foyer" one finds that it is in part an actual lounge room from a 1950s home on the original site that has been incorporated into the new museum (this home was designed by Australian modernist architect Roy Grounds). This is an unexpected allusion to domestic intimacy, and one is further surprised to discover that ingress to the exhibition spaces is obtained by descending a spiral staircase where one eventually comes to the "start" of the museum, which is on a third floor basement level. There are three basement level floors, as well as catacombs and a tunnel that links the museum to original heritage buildings above ground. This means the site resembles an adventure playground. The most spectacular part of the interior is a wall that consists of a 143-meter long Triassic sandstone cliff that was excavated into the riverbank of the peninsula (Picture 7). The sandstone walls make a dramatic impact and act as theatrical scenery, and this unusual feature is combined with cantilevered mezzanine floors that open up the various levels to multiple perspectives. This adds excitement, drama and an additional sense of theatre to the venue.

Picture 7. Museum of Old and New Art (interior), Hobart

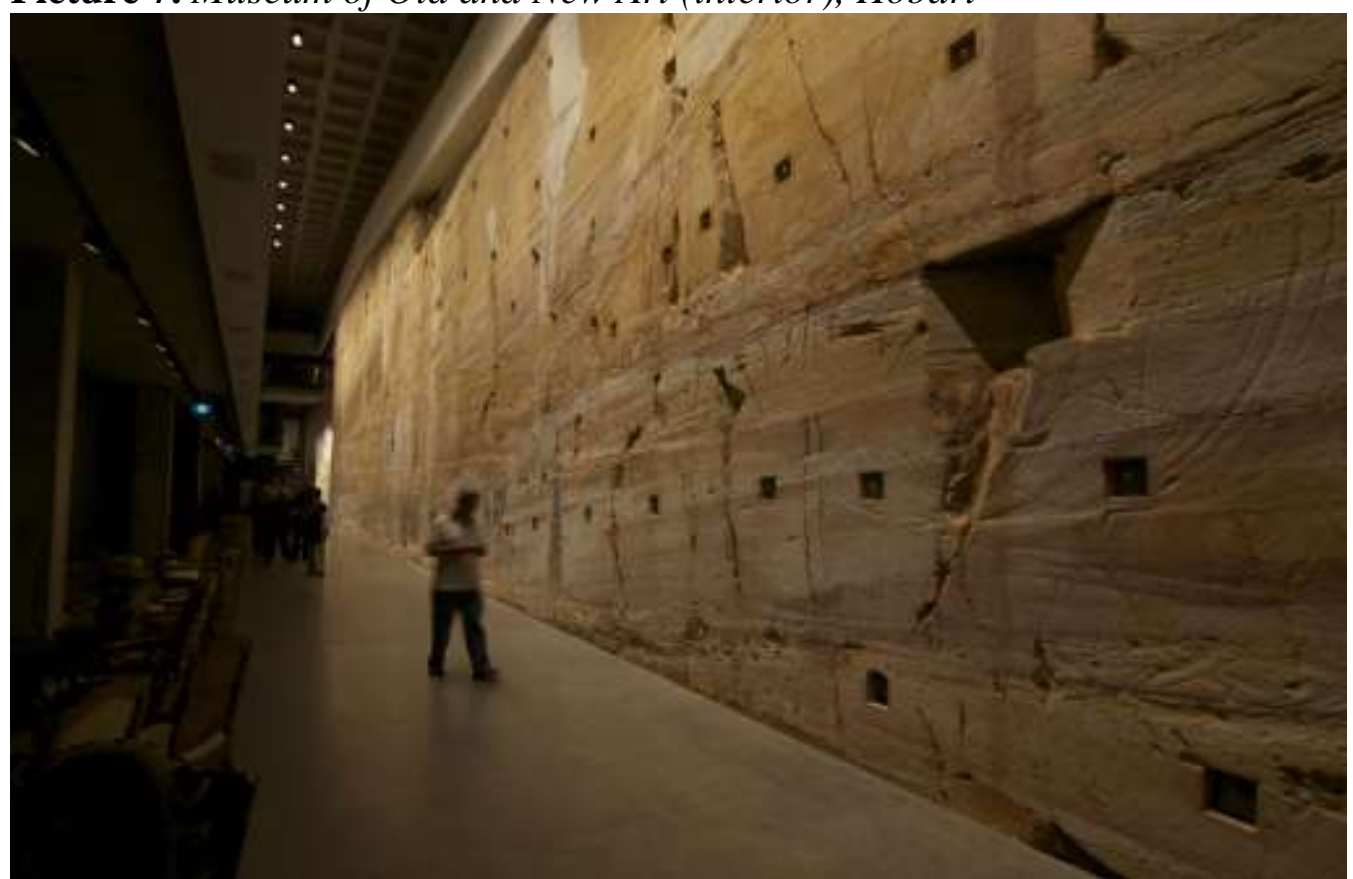

Source: Photography by Christopher Neugebauer. https://www.flickr.com/photos/chrisjrn/ 8058869169. 
Walsh's patchwork collection spans diverse periods: from Minoan funerary caskets to radical contemporary art. To make the most of this, the art is exhibited in "configurations" with works from different historical periods inhabiting the same gallery spaces. This militates against a linear navigation of the galleries, so the viewer is soon meandering through an immersive "dreamscape", and must explore the space without guidance. The spaces are also darkly illuminated, not brightly lit, and there are no wall labels. The absence of wall labels further disrupts the conventional viewing experience of art, for without them the viewer must engage with the displays on a more sensory and phenomenological level, without necessarily relying on intellectual or critical assessments. This transforms the experience of art from older didactic bourgeois tradition in which the populace is taught "how" to understand an artwork, towards a non-guided theatrical experience more in keeping with entertainment modes.

Walsh is an unabashed populist. He rejects the didactic and authorial air of many art museums, and wants his space to be "different". In response, the experience offered by MONA is one in which the viewer is given greater agency to negotiate the space on his/her own terms, for one is not physically and intellectually directed. The majestic sandstone walls and dramatically darkened spaces add an awe-inspiring theatre of experience that is decidedly populist in orientation. MONA is indeed a populist entertainment complex, but has also succeeded in attracting the support of art cognoscenti and professionals who recognize the liberating value of allowing visitors to imbibe art on their own terms, rather than be directed by those who may represent an elite notion of art and culture. MONA also manages a winter festival called Dark Mofo (with government tourist agencies), which has art, film, music and banquets.

The museum is part of a cultural precinct that includes the museum, a vineyard, entertainment stages and vacation accommodation. In addition, MONA's riverine connection to Hobart serves to enhance and extend that city as an experiencescape. MONA lies in one of Hobart's outer suburbs and is a 20-minute ferry ride from the capital. The ferry departs from Hobart's central docks and traverses the beautiful Derwent River, and the ferry pilot acts as a tour guide by pointing out historical features along the route. The ferries are also promoted as "MONA" ferries and travellers can pay for a luxury berth (called the "posh pit") that includes fine wine and a gourmet meal. Visitors are also offered various transport options to the museum, including a helicopter, and a chauffer driven Audi.

With its idiosyncratic and boutique profile MONA has made a spectacular contribution to Tasmania's tourism industry. It is the most popular tourist attraction in the state, receives 350,000 visitors a year, and helps bring in $\$ 79$ million annually. Local newspapers have lauded the museum, claiming that Tasmania's "tourism industry is riding the wave of a MONA-led revolution, with visitor numbers smashing previous records; Tourism groups were yesterday celebrating results of the latest Tasmanian Visitor Survey, which showed a $14 \%$ jump in numbers for the year ending last December. The boost 
resulted in a $13 \%$ increase in visitor spending, to $\$ 1.58$ billion." The chief executive of the Tourism Industry Council of Tasmania (Luke Martin) added, "It's the MONA effect ... It's more than just the product itself; it's generated interest and awareness in Tasmania which has made us stand out in the market" (Martin 2014).

MONA is also of interest because Walsh has recently declared an interest in establishing a casino called "Monaco" that will be aimed at "super wealthy art lovers from around the world" (Glaetzer 2014). There are art museums that have already combined art and gambling, such as the Bellagio Hotel, casino and art museum in Las Vegas (to which the Boston Museum of Art loaned 21 Monet paintings in 2004). A branch franchise of the Guggenheim-Hermitage art museum (designed by stararchitect Rem Koolhaus) is also in Las Vegas, and opened in the Venetian Hotel with gambling facilities. The Mashantucket Pequot Native American Museum in Nantucket in Connecticut also combines the art and gambling experience. Given the transformation of art museums into experience centers these sites will be increasingly used as venues that can be rented out for business enterprises that want to exploit the venerable reputations of established museums, and the exciting design of new buildings, to enhance sales potential. ${ }^{1}$

\section{Conclusions}

The experiencescape articulates many important new tendencies in urban infrastructure and the role of art museums, and reveals how vital tourism is to the economics of global cities in the early twenty-first century. It signals a new model for urban planning and design in a neoliberal era, and shows how entire environments are being transformed in recognition of experience as an important economic and cultural offering. As the roles of art museums are undergoing major change they have become very important features in the tourist market, and on occasion are the pivots around which experiencescapes are organized. Art is now a firm part of the experiential entertainment economy and the urban complexes that give it shape. Moreover, as MONA has successfully demonstrated, by investing in the tourist as primary art audience, art museums are less interested in appealing to an older "core audience" of academics, art insiders, and university students, and are now functioning as a vital conduit in the valorization of intangible cultural experiences and their translation into tangible economic outcomes.

\footnotetext{
${ }^{1}$ This is not an entirely new phenomenon given that since at least the 1980s many art museums have sold their sites as advertising venues for corporations that sponsor blockbuster exhibitions.
} 


\section{References}

Edgers G (2014) Los Angeles cultural boom gives city's artists spaces they can call home. The Guardian Weekly October 31: 41.

Ek R (2005) Regional Experience-scapes as Geo-economic Ammunition. In T O'Dell, P Billing (Eds.) Experience-scapes. Tourism, Culture And Economy. Copenhagen: Copenhagen Business School Press.

Falk JH, Dierking LD (2000) Learning from Museums: Visitor Experiences and the Making of Meaning. Lanham, USA: Alta Mira Press.

Foster H (2011) The Art-Architecture Complex. London: Verso.

Glaetzer S (2014) Philantrhopist David Walsh wants to build casino at MONA. Tasmanian Mercury [Online] September 29. Retrieved from http://goo.gl/OE e4Em.

Huppatz DJ (2008) Cultural globalization and the Post-Bilbao Museum. Art and Australia 46(2)(Summer): 200-205.

Jensen, Soren Henning (2005) Promoting the Known and the Unknown of Cities and City Regions. In T O'Dell, P Billing (Eds.) Experience-scapes. Tourism, Culture and Economy. Copenhagen: Copenhagen Business School Press.

Klingmann A (2010) Brandscapes, Architecture in the Experience Economy. MIT Press.

Krasny E (2010) Unter einem rot hut [ ]. Architektur Aktuell. 364/65 (July/August).

Lonsway B (2009) Making Leisure Work: Architecture and the Experience Economy. London/New York: Routledge Press.

Martin H (2014) World Class MONA helps Tassie Smash tourism record. Tasmanian Mercury [Online] April 10. Retrieved from http://goo.gl/UWfeIp.

Martins SB (2014) Port of call. Art Forum 52(9/May): 282-285.

Moore JF (1996) The Death of Competition: Leadership \& Strategy in the Age of Business Ecosystems. New York: Harper Business.

O'Dell T (2005) Experience-scapes. In T O'Dell, P Billing (Eds.) Experience-scapes. Tourism, Culture and Economy. Copenhagen: Copenhagen Business School Press.

Peltoniemi M, Vuori E (2004) Business Ecosystem as the New Approach to Complex Adaptive Business Environments. Research Gate [Online] Retrieved from http://goo.gl/M0eYrG.

Robertson K (2011) Titanium motherships of the new economy: museums, neoliberalism and resistance. In $\mathrm{K}$ Cronan, $\mathrm{K}$ Robertson (Eds.) Imagining Resistancs. Toronto: Wilfred Laurier Press.

Stallabrass J (2004) Art Incorporated. The Story of Contemporary Art. Oxford: Oxford University Press.

Travel Daily News (2014) China to dominate Asia outbound travel by 2030. Travel Daily News. Asia-Pacific [Online] 30 January. Retrieved from http://goo.gl/ Flt4FI.

Wu CT (2003) Privatizing Culture: Corporate Art Intervention since the 1980s. London: Verso.

Yúdice, George (2004) The Expediency of Culture: Uses of Culture in the Global Era Durham: Duke University Press Books. 
